\title{
IDENTIDADE PROFISSIONAL DO PROFESSOR SEM IDENTIDADE COM O ENSINO: CRÍTICA À EPISTEMOLOGIA DA PRÁTICA ${ }^{1}$
}

\author{
Saulo Rodrigues de Carvalho ${ }^{2}$
}

\begin{abstract}
RESUMO
Este trabalho discute o conceito de Identidade Profissional do Professor, sob o enfoque da Pedagogia Histórico-Crítica e Psicologia Histórico-Cultural. Trata-se de uma pesquisa em regime especial da UNICENTRO $(\mathrm{PqE})$ e igualmente é parte dos estudos realizados para a tese de doutorado vinculada ao Programa de pós-graduação em educação escolar da Faculdade de Ciências e Letras - UNESP/Araraquara. Analisa de maneira crítica a pertinência do conceito de Identidade Profissional do Professor, como princípio para a compreensão de sua personalidade no contexto da reestruturação produtiva do capital. Nesse sentido apontamos a formação de uma identidade do professor que não se identifica com o ensino. Por fim discutimos a insuficiência da identidade do professor circunscrita a sua particularidade profissional e a necessidade histórica da apreensão da universalidade do trabalho educativo.

Palavras-chave: Identidade Profissional do Professor; Epistemologia da Prática; Pedagogia Histórico-Crítica; Psicologia Histórico-Cultural; Educação Escolar.
\end{abstract}

\section{PROFESSIONAL TEACHER IDENTITY NO IDENTITY WITH TEACHING: CRITICAL TO PRATICE EPISTEMOLOGY}

\begin{abstract}
This work discusses the concept of Professional Teacher Identity with focus on the Historico-Critical Pedagogical and Historico-Cultural Psichology. It is a research in special system of the UNICENTRO $(\mathrm{PqE})$ and is part of the studies for doctoral thesis connected to the Program Postgraduate in School Education of the Faculdade de Ciências e Letras UNESP/Araraquara. Analyzes critically the relevance the concept of Professional Teacher Identity as a principle to understanding of the your personality in contexto of the productive restructuring of capital. In this sense, we point the formation of an identity of the teacher who does not identify with the school. We discuss the insufficiency of Professional Teacher Identity limited the for his professional particularity and and the historical necessity of understanding of the universality of the educational work.

Keywords: Professional Teacher Identity; Epistemology of Pratice; Historico-Critical Pedagogical; Historico-Cultural Psichology; School Education.
\end{abstract}

\section{Introdução}

Neste artigo discutiremos a identidade profissional do professor e suas aproximações com a teoria do professor reflexivo. Com base nos preceitos da epistemologia da prática a Identidade profissional que se propõe ao professor tem como referência a formação de competências e habilidades, que estão ligadas aos novos processos de produção. As formas de produzir e consumir, inauguradas pelas mudanças do avanço tecnológico da sociedade teriam alterado substancialmente a disposição de aprender e ensinar detonando uma crise de identidade do trabalho docente. A iminência de uma nova profissionalidade fundada nos padrões da atualidade globalizada do trabalho é 
apresentada ao professor como forma de vencer a crise, adotando uma identidade profissional dedicada a refletir e resolver os problemas apresentados pela prática docente cotidiana.

Sob a perspectiva do materialismo histórico, argumentamos oposto dessa tese. Sem negar que as novas tecnologias provocaram alterações globais nas diversas esferas da atividade humana, inclusive no trabalho docente, consideramos que os efeitos produzidos pelo seu emprego recaem principalmente, sobre a maneira de exploração do trabalho pelo capital. Em conformidade com esta etapa do desenvolvimento capitalista (sua crise permanente) o professor é convidado a se identificar com as formas de produção e reprodução do conhecimento e principalmente com a maneira de educar a força de trabalho da reestruturação produtiva do capital. Sobressai dessa ordem certa desconfiança com o conhecimento objetivo, uma vez que eles podem ser dispensados para a configuração da força de trabalho, são os saberes intuitivos que prevalecem na educação da massa dos trabalhadores. O irracionalismo desponta nas teorias pedagógicas em defesa da individualidade dos sujeitos, colocados agora como demiurgos do conhecimento. Em contrapartida o professor deve se afastar cada vez mais das formas de ensinar, para auxiliar os alunos a "aprender a aprender".

Por outro lado, a educação escolar por meio de seu ensino dirigido exerce um papel privilegiado no desenvolvimento do pensamento. Com base na Psicologia HistóricoCultural e na Pedagogia Histórico-Crítica reafirmamos a centralidade da educação escolar, fundada no reconhecimento das formas mais desenvolvidas (que nem sempre se identificam com as mais novas) do saber objetivo e a maneira mais adequada de transmitilo, de modo que se incorporem ao ser dos indivíduos (SAVIANI, 2012). Um professor que não ensina e não transmite os conhecimentos culturais desenvolvidos pela humanidade, não possui os "instrumentos" adequados para promover nos indivíduos "a humanidade que é produzida histórica e coletivamente pelo conjunto dos homens" (SAVIANI, 2012, p.13). Da mesma forma, a chave do desenvolvimento das funções psicológicas superiores, encontra no ensino que ultrapassa o desenvolvimento da maturidade da criança, elevando seu pensamento ao domínio das operações lógicas e abstratas e ao próprio domínio de si. Desta forma, Psicologia Histórico-Cultural e Pedagogia Histórico-Crítica atestam o ensino como primeira condição para o exercício da docência, desconstruindo, os discursos que reiteram a necessidade de um profissionalismo do professor descolado da atividade de ensino.

No mais, apontamos para um exame do conceito de identidade do professor buscando a sua superação. Para compreensão do trabalho do professor e da sua função social os elementos que correspondem a sua identidade, parecem insuficientes, sendo necessário, porém, perfilhar a essencialidade de sua ação educativa concatenada a um projeto de emancipação humana e superação do capital.

\section{Localizando a Epistemologia da Prática como base teórica para a identidade profissional do professor.}

Temos escutado nas escolas, lido nos jornais e visto nos debates, um grande clamor por "mais prática" nas salas de aula. Não só a mídia mais reacionária e os discursos oficiais buscam explicar a falência do sistema educacional ancorando-se na ausência de uma formação prática dos professores, como também grupos conhecidos por exigir mudanças mais progressistas na educação, têm referendado tal tese. A explicação mais comum para essa "virada" da prática, encontra-se na afirmação linear e não-contraditória das transformações ocorridas nas ultimas décadas, prioritariamente no campo das tecnologias 
da informação e comunicação, que teriam alterado significativamente o campo do ensino e da aprendizagem dos indivíduos.

Decorrente desse escólio o conhecimento escolar caracterizado, nessa perspectiva, por uma natureza conteudista e mecanicista, deveria ser suplantado por outra forma de saber. Uma vez que os conhecimentos, por meio da "revolução da informática", tomando Schaff (1990) por referência, estão disponibilizados aos indivíduos que, à sua maneira, são "bombardeados" cotidianamente por "novos conhecimentos", cabe à educação escolar não mais ensinar, mas sim orientar os indivíduos a organizarem os conhecimentos que lhes serão necessários à inserção na dinâmica global da sociedade em curso.

Nessa direção diversos discursos pedagógicos se levantaram na tentativa de teorizar uma solução paradigmática para a redefinição do papel da educação escolar. A epistemologia da prática se constitui num desses discursos. No seu estofo teórico coadunam a formação por "competências" e os princípios do "aprender a aprender". Substancialmente se objetiva na reorganização do trabalho docente tendo como parâmetro o conhecimento adquirido pela prática profissional, caracterizando o professor como profissional reflexivo (SCHÖN, 2000).

Facci (2004) ao estudar o esvaziamento do trabalho do professor identifica o aparecimento desse conceito já na década de 1960 na Inglaterra, como contraposição a concepção tecnocrática da docência. Contudo, são nos anos de 1980, com as publicações de Donald Schön a respeito da requalificação profissional, pautando a formação de profissionais reflexivos, que essa concepção volta a ganhar notoriedade. Seus estudos sobre a prática profissional tiveram início na década de 1970, quando o diretor da Escola de Arquitetura e Planejamento do M.I.T ${ }^{3}$ convidou-o a participar de uma pesquisa sobre educação e arquitetura daquele departamento (SCHÖN, 2000). A partir de então, Schön dedicou-se ao estudo da formação profissional proposto pelas universidades. O destaque de seu trabalho passou rapidamente a compor o referencial de propostas pedagógicas destinadas a repensar a educação compondo com outros referenciais teóricos, como o construtivismo piagetiano e as pedagogias da competência, o universo do "aprender a aprender". Segundo sua teoria as novas formas de organização do trabalho propiciaram à formação de um profissional fundamentado na reflexão sobre os problemas apresentados pela prática. Não havendo mais espaço, dali em diante, para modelos pré-estabelecidos de resolução de problemas (aplicação de uma teoria à um problema prático), caberia ao novo profissional aprender a refletir sobre sua experiência.

Retomando os estudos de John Dewey sobre o “aprender fazendo”, Schön elabora o que seriam alguns dos níveis de conhecimento que perfazem a constituição do processo de reflexão, o conhecimento-na-ação, a reflexão-na-ação, a reflexão-sobre-a-ação e a reflexão-sobre-a-reflexão-na-ação (SCHÖN, 2000). Prioritariamente, Schön propõe esse modelo à formação de professores em simetria às exigências da sociedade contemporânea. Para ele "o saber sobre o ensino não se daria antes do fazer [...] iniciar-se-ia pelo questionamento da prática respaldado em conhecimentos teóricos, seria produto do entendimento dos problemas vivenciados e da criação de novas soluções visando sua superação" (SCHÖN, 2000, p. 91). Diferente da formação tradicional de professores, (estudo da teoria e aplicação prática no estágio), o professor reflexivo aprenderia com sua própria prática, aplicando as teorias que correspondessem aos obstáculos despontados pela prática em sala de aula.

Muito embora possa ser discutível um ou outro traço da proposição de $\operatorname{Schön}^{4}$ para a formação de professores reflexivos, essencialmente a sua teoria tem sido o baluarte das discussões em torno da "recuperação" ou "reformulação" da identidade profissional do professor, perdida nos entrementes das "mudanças globais da sociedade". De outro modo, 
quero ressaltar que no cerne do debate por uma identidade profissional do professor, encontra-se demarcado hoje o agenciamento da teoria da prática reflexiva. Adiante exploraremos os problemas que abarcam o assinalamento de uma identidade professor, ante a epistemologia da prática.

\section{Epistemologia da Prática e os Problemas em ensinar}

Intrínseco ao fato de que na espinha dorsal de todas as construções teóricas sobre as "novas" formas de ensinar e aprender encontra-se engastada uma completa desconsideração pela objetividade do conhecimento, a epistemologia da prática incorpora a esse enunciado um critério valorativo dando maior importância ao conhecimento tácito. Diferente do conhecimento científico que prima pela sua exatidão, pela sua perfeita e correta enunciação, o conhecimento tácito é aquele que não é explícito, é aquele que fica subentendido nas ações, ele não pode ser claramente descrito, uma vez que pertence sempre a esfera da particularidade dos indivíduos. Como salienta Teixeira (2013), o conhecimento tácito possui uma característica pessoal e por isso apresenta dificuldades de ser apresentado "[...] em termos lógicos por fazer parte da própria 'idiossincrasia' do indivíduo e segundo modelos mentais pessoais, manifestando-se como elemento implícito e inconsciente em suas ações, sendo muitas vezes identificado como habilidades inatas" (p.23).

Nesta feita, como cada indivíduo reage de forma diferente e irrepetível uns dos outros a determinadas situações do cotidiano, em sua singularidade individual possuem sua própria interpretação do real. São as consciências individuais isoladas que "constroem" o saber, sendo, portanto, a reunião dessas consciências que validarão ou não a utilidade desses conhecimentos. O saber científico, neste caso, eleva-se a alcunha de cientificidade não por sua objetividade, mas pela convenção daquilo que se caracterizou como científico. Por esse motivo a teoria para o professor reflexivo, torna-se apenas um item acessório, que lhe auxiliará a chegar aos conhecimentos necessários à resolução de determinado problema prático.

Se o essencial para a epistemologia da prática está no modo em que cada indivíduo resolve os problemas apresentados por sua atividade prática, se o conhecimento válido é aquele que está implícito, aquele que não pode ser descrito com exatidão, aquele que não pode ser universalizado, então temos uma situação em que não se pode ensinar aquilo que não pode ser aprendido. A este ponto a epistemologia da prática resolve o problema do ensino incorporando à sua teoria o modelo de desenvolvimento das competências (PERRENOUD, 1999, 2000). Cabe ao professor "aprender" a selecionar e por em ação as habilidades que lhe são próprias à sua atividade docente, ter a "capacidade de mobilizar diversos recursos cognitivos para enfrentar um tipo de situações" (PERRENOUD, 2000, p.15), promovendo nos alunos o "despertar" de suas competências, no limiar do atendimento às demandas sociais que lhes são apresentadas. Ensinar torna-se um problema à prática do professor reflexivo que tem como tarefa ajudar o aluno a aprender a pensar com suas próprias forças, colocando-o em situações que "possam exigir criatividade e iniciativa, uma vez que estas carregam em si mesmas a possibilidade de liberação das potencialidades de cada aluno" (CUNHA, 1998, p. 46).

Para Schön (2000) o tipo de ensino formal praticado nas universidades ${ }^{5}$ inibiria o desenvolvimento da competência profissional, uma vez que se trata da "competência e o talento já inerentes à prática habilidosa - especialmente a reflexão-na-ação" (prefácio, p.VII, grifo nosso). Ao que tudo indica o conhecimento profissional para Schön é intrínseco ao indivíduo que o realiza, compondo uma parte do talento, da inclinação 
natural do individuo para a prática de determinada atividade, designado muitas vezes para caracterizar pessoas muito habilidosas, principalmente no campo artístico. Assim nas palavras de Schön (2000) para aprender o talento artístico profissional seria preciso estabelecer

[...] condições semelhantes àquelas criadas nos ateliês e conservatórios: liberdade para aprender através do fazer, em um ambiente de risco relativamente baixo, com acesso a instrutores que iniciem os estudantes nas "tradições da vocação" e os ajudem, através da "fala correta", a ver por si próprios e à sua própria maneira o que eles mais precisam ver. (p.25)

Mas, o termo talento trás de fato outra conotação fundamental, a de concepção de indivíduo para o liberalismo, que como define Hayek (1977) orienta-se por um:

[...] respeito pelo homem individual na qualidade de homem, isto é, a aceitação de seus gostos e opiniões como sendo supremos dentro de sua esfera, por mais estritamente que isto se possa circunscrever, e a convicção de que é desejável o desenvolvimento dos dotes e inclinações individuais por parte de cada um (p. 35, grifo nosso).

Abstraindo a divisão do trabalho como força social determinante na vida dos indivíduos, o liberalismo compreende o profissionalismo como uma casualidade dirigida pelas escolhas individuais, baseada nas inclinações e aptidões pessoais, que são naturalmente desenvolvidas. Também desta forma, o professor reflexivo interage com o aluno, afim de que este possa descobrir e aplicar suas competências pessoais para o melhor desenvolvimento de sua profissão. Uma vez que cada indivíduo desenvolve de maneira singular seus gostos, seus valores e seu conhecimento sobre o mundo, as formas tradicionais fixadas na transmissão generalizada do conhecimento são substituídas por formas individuais de apropriação do conhecimento. Não cabe ensinar, mas auxiliar os indivíduos a "aprenderem" a buscar os conhecimentos que melhor respondem às suas inquietações pessoais. Tomado como horizonte para a resposta aos problemas propostos pela "sociedade em constante mudança", marcada por situações de "conflito" e "incerteza", a epistemologia da prática não somente se lança como uma teoria para a formação profissional do professor, como também se apresenta nos discursos de "construção da identidade docente".

\section{Identidade Profissional do Professor que não ensina ou a identidade profissional do professor da reestruturação produtiva do capital.}

"Que saudade da professorinhal Que me ensinou o be-a-bá...."

Ataulfo Alves identificou na sua professora o seu primeiro amor, mas identificava também no ensino a forma peculiar do trabalho do professor. É claro que esse é um exemplo um tanto descontextualizado do quanto o ensinar e o conhecimento escolar caracterizaram popularmente o trabalho docente. No entanto, é preciso afirmar que essa identificação do professor com o ensino, com o conhecimento dos conteúdos e das formas de transmissão do saber, foi uma conquista histórica dessa categoria profissional. No Brasil, Saviani (2009) nos mostra que a preocupação por uma formação adequada ao 
magistério destinado à formação geral da população, ainda que de maneira tímida, data-se a partir da proclamação da república brasileira.

Durante todo o período colonial, desde os colégios jesuítas, passando pelas aulas régias implantadas pelas reformas pombalinas até os cursos superiores criados a partir da vinda de D. João VI em 1808, não se manifesta preocupação explícita com a questão da formação de professores. É na Lei das Escolas de Primeiras Letras, promulgada em 15 de outubro de 1827, que essa preocupação apareceu pela primeira vez. (SAVIANI, 2009, p.144)

Com a instituição da Lei das Escolas de Primeiras Letras, os professores brasileiros ganham de uma só vez, uma escola de formação para o magistério e um método de ensino a ser aplicado. De olho no que acontecia na Europa as Escolas Normais do Brasil, deveriam preparar os professores no espírito pedagógico do Método Mútuo ${ }^{6}$, estabelecendo como requisito o "[...] preparo pedagógico embora não se faça referência propriamente à questão pedagógica”. (SAVIANI, 2009, p. 144). Mais tarde as Escolas Normais Superiores exerceriam um papel predominante na elaboração de uma formação especifica didáticopedagógica do trabalho docente.

No entanto, contrariamente a essa expectativa, predominou nelas a preocupação com o domínio dos conhecimentos a serem transmitidos nas escolas de primeiras letras. O currículo dessas escolas era constituído pelas mesmas matérias ensinadas nas escolas de primeiras letras. Portanto, o que se pressupunha era que os professores deveriam ter o domínio daqueles conteúdos que lhes caberia transmitir às crianças, desconsiderando-se o preparo didático-pedagógico. (SAVIANI, 2009, p. 144)

O domínio do conteúdo escolar passava a figurar-se num atributo que solidificava e caracterizava o trabalho do professor no âmbito profissional, embora lhe faltasse o preparo didático-pedagógico. As Escolas Normais eram muito onerosas às Províncias e não cobriam as necessidades com a educação, formando poucos professores passando por um "período intermitente", fechando e reabrindo periodicamente (SAVIANI, 2009). Em 1890 a Reforma da Instrução Pública do Estado de São Paulo, serviu de base para fixar o modelo de formação das Escolas Normais por todo país. Segundo Saviani (2009)

A reforma foi marcada por dois vetores: enriquecimento dos conteúdos curriculares anteriores e ênfase os exercícios práticos de ensino, cuja marca característica foi a criação da escola-modelo anexa à Escola Normal - na verdade a principal inovação da reforma. Assumindo os custos de sua instalação e centralizando o preparo dos novos professores nos exercícios práticos, os reformadores estavam assumindo o entendimento de que, sem assegurar de forma deliberada e sistemática por meio da organização curricular a preparação pedagógico-didática, não se estaria, em sentido próprio, formando professores (p.145)

A larga formação cultural por si só não bastava para a preparação do professor, que deveria ser complementada pelo exercício da prática. Nesse aspecto as escolas-modelo são instituídas para servir como campo de observação para os futuros professores aprenderem a profissão em similitude com a prática real. 
Prevalecia o aprendizado na visibilidade e imitabilidade das práticas pedagógicas, além disso, era responsabilidade das escolas modelo disseminar os métodos de ensino considerados mais modernos e apropriados, bem como práticas avançadas de organização da vida escolar. (CANDIDO, 2007, p.123)

Mudando o que precisa ser mudado, o professor foi se constituindo num profissional com alto domínio da cultura e acuidade técnica, especializando-se e buscando aplicar os métodos e práticas escolares correspondentes ao que era considerado o máximo desenvolvimento do campo didático-pédagógico.

Com a modernização capitalista e a necessidade de ampliar o quadro profissional do país em face da industrialização, a criação do ensino profissionalizante e a expansão do sistema escolar com as reformas da era Vargas, lançaram um novo desafio à carreira docente, introduzindo a pesquisa como requisito ao exercício da pedagogia. Os Institutos de Educação criados em 1932, “[...] foram pensados e organizados de maneira a incorporar as exigências da pedagogia, que buscava se firmar como um conhecimento de caráter científico" (SAVIANI, 2009, p. 146). Rapidamente, os Institutos foram elevados a condição de Ensino Universitário em 1939, responsabilizando-se pela formação de professores para atuar nas escolas secundárias e nas Escolas Normais que continuaram, a formar professores para o ensino primário sob nova estrutura que se dividia em dois ciclos, como explica Saviani (2009)

[...] o primeiro correspondia ao ciclo ginasial do curso secundário e tinha duração de quatro anos. Seu objetivo era formar regentes do ensino primário e funcionaria em Escolas Normais regionais. O segundo ciclo, com a duração de três anos, correspondia ao ciclo colegial do curso secundário. Seu objetivo era formar os professores do ensino primário e funcionaria em Escolas Normais e nos institutos de educação. Estes, além dos cursos citados, contariam com jardim de infância e escola primária anexos e ministrariam também cursos de especialização de professores primários para as áreas de Educação Especial, Ensino Supletivo, Desenho e Artes aplicadas, música e canto e cursos de administradores escolares para formar diretores, orientadores e inspetores escolares. (p.146)

Ainda que de maneira muito problemática, o professor foi se constituindo num profissional de amplo domínio da cultura, com grau elevado de especialidades técnicocientíficas, que correspondia até o final dos anos de 1960, no Brasil, com certo status social das classes médias.

Em 1964 os militares tomam as rédeas do processo de industrialização capitalista brasileiro, instaurando uma ditadura civil-militar ${ }^{7}$ que permaneceria oficialmente até 1985. Dentre outras finalidades político-ideológicas, o governo dos militares buscou acelerar a industrialização do país dando salvaguardas ao capital internacional, incentivando às corporações multinacionais, forjando uma força de trabalho economicamente fragilizada e politicamente entorpecida.

O pretexto de conter a inflação, o novo regime operou a estagnação dos salários pela força, a restrição ao crédito, levando à falência centenas de pequenas e médias indústrias, a concentração da produção e da renda, pela destruição da concorrência e incentivo as fusões. Mas operou também, pelo congelamento de preços das matérias-primas produzidas 
pela área estatal, o aço como a mais destacada delas. A siderurgia foi levada ao limite máximo, subsidiando violentamente as indústrias estrangeiras a que fornecia (SODRÉ 1982, p.143)

Para abastecer a nova base industrial foi preciso massificar a educação da força de trabalho, expandindo o ensino secundário a toda população transformando-o compulsoriamente em ensino profissionalizante (PINTO e outros, 2011). Era preciso, ao mesmo tempo, abastecer o sistema com profissionais da educação para os novos setores incluídos na estrutura educacional. A formação de professores foi tornando-se cada vez mais aligeirada, ao passo que sua finalidade passava a ser o atendimento das escolas de massa. Como salienta Pinto e outros (2011) "O resultado foi uma expansão a baixo custo, multiplicando-se os turnos escolares e achatando-se os salários, com prédios precários, professores mal preparados e desmotivados, lançando as raízes de nossa atual escola de massas e para as massas, em oposição às escolas da elite" (p. 642). Para as classes trabalhadoras um ensino escolar cada vez mais em "doses homeopáticas", o que acarreta por outro lado, em formar professores que cada vez sabem menos.

A partir da década de 1970 o status profissional do professor no Brasil começa a ser ameaçado. Materialmente o professor se vê acometido de constantes perdas salariais que acompanham a desconsideração pela sua formação como aponta Saviani (2009)

Pelo parecer n. 349/72 (Brasil-MEC-CFE, 1972), aprovado em 6 de abril de 1972, a habilitação específica do magistério foi organizada em duas modalidades básicas: uma com a duração de três anos (2.200 horas), que habilitaria a lecionar até a $4^{\mathrm{a}}$ série; e outra com a duração de quatro anos (2.900 horas), habilitando ao magistério até a $6^{\mathrm{a}}$ série do $1^{\mathrm{o}}$ grau. $\mathrm{O}$ currículo mínimo compreendia o núcleo comum, obrigatório em todo o território nacional para todo o ensino de $1^{\circ}$ e $2^{\circ}$ graus, destinado a garantir a formação geral; e uma parte diversificada, visando à formação especial. $\mathrm{O}$ antigo curso normal cedeu lugar a uma habilitação de $2^{\circ}$ Grau. A formação de professores para o antigo ensino primário foi, pois, reduzida a uma habilitação dispersa em meio a tantas outras, configurando um quadro de precariedade bastante preocupante. (SAVIANI, 2009, p.147)

Na década de 1980, o fim da ditadura militar não trouxe grandes melhorias em termos de ganhos profissionais aos professores. A abertura democrática permitiu a reorganização dos sindicatos e fortaleceu a organização política dos professores, que se organizaram em torno de mudanças estruturais na educação, como a LDB de 1996 e a instituição do Plano Nacional de Educação (PNE). No entanto, a base do neoliberalismo lançada pela ditadura dos militares seguiu como plataforma política dos governos democráticos que se sucederam.

No plano educacional, seguindo os ditames internacionais, a política de redução de custos do Estado nos setores sociais e privatização da economia nacional operaram na inversão de prioridades do Estado na formação de professores. Na década de 1990 o setor privado toma a frente da Educação Superior, passando deste modo a cobrir a maior parte da formação dos professores, com a criação de cursos de licenciatura cada vez mais aligeirados e superficiais.

Em meio à crise de acumulação capitalista ${ }^{8}$ e as novas formas de organização da produção, o fim do Welfare States nas economias de capitalismo desenvolvido, demarcou também o trágico final das políticas públicas estatais. Nas periferias do capitalismo o objetivo da educação se voltaria à formação para a competitividade num mercado de trabalho cada vez mais restrito. 
Nas bases econômicas a reestruturação produtiva se impôs como tendência fundamentada na incorporação de um alto padrão de tecnologia e a dispensa de grandes quantidades de mão de obra como critério para o rebaixamento do valor da força de trabalho.

A reestruturação produtiva do capital é, por outro lado, um reflexo do acréscimo exponencial da propriedade capitalista, do seu "Capital Constante" (Marx, 2002), e o emprego é cada vez mais reduzido da força de trabalho (sua intensificação) no aumento das taxas de mais-valia. Nessa configuração, a absorção da maior parte da força de trabalho está locada em pontos que exijam baixa qualificação, ligados a empresas terceirizadas e setores de serviço. (CARVALHO e MARTINS, 2013, p.144)

De outra forma o semblante do "novo capitalismo" assegurava o surgimento de uma nova era, fundada no domínio do conhecimento. Contraditoriamente a transmissão do conhecimento é apresentada como inoportuna, uma vez que na "Sociedade do Conhecimento" o mais importante é o aprendizado do indivíduo por si mesmo, construído livremente e não recebido de fora. Para isso não é preciso ensinar, basta apenas que o professor facilite aos indivíduos construção do conhecimento.

Em pouco mais de uma década o professor encontra-se numa posição de esvaziamento do sentido de sua atividade e desvalorização da sua força de trabalho. No entanto, a cantilena "pós-moderna" apoia seu discurso na complexificação das relações sociais ocasionada pelas descobertas tecnológicas, que invariavelmente comutariam as formas de educação dos indivíduos, tornando o trabalho do professor cada vez mais ilegível e conflituoso.

Consequentemente, uma sensação de "mal-estar" recai sobre o trabalho docente, que se vê pressionado, desmotivado e mal remunerado. Como apontam Martins (2007) e Facci (2004) muitos estudos no campo da teoria do professor reflexivo, localizaram no mal-estar docente a gênese de uma crise de identidade dos professores. A resposta a tal crise identitária estaria dada na formação de uma nova profissionalidade, condizente com a realidade atual da educação e a complexidade da sociedade do conhecimento.

Todavia a identidade profissional do professor "[...] se constrói, pois com base na significação social da profissão [...]" (PIMENTA, 2002, p.77), no constructo individual que cada professor confere à sua atividade docente cotidiana com base na representação dos valores e conhecimentos em torno da sua vida profissional. Com base nesta identidade, entre a docência e a vida pessoal, o profissionalismo que se requer do professor reflexivo, incute na sua própria forma de pensar a profissão com devoção às soluções encontradas às barreiras que se interpõem no cotidiano escolar.

Da mesma forma essa identidade está interligada processualmente ao modo de concepção do conhecimento no capitalismo contemporâneo, formando professores que estão sempre prontos para encontrar soluções à aprendizagem dos alunos em conformidade com as demandas sociais (identificadas principalmente pelo mercado de trabalho). Um professor que não ensina, mas que forma competências e habilidades.

A nosso ver, sem exagerar na tintura, são catastróficas as consequências da adoção da Identidade profissional do professor em afinidade estrutural com as transformações do capital, ao trabalho educativo. Na sequência deste artigo buscaremos frisar a centralidade do conteúdo escolar para o ato educativo, apresentando suas bases pedagógicas e desdobramentos psicológicos na formação da consciência dos indivíduos, salientando os 
riscos ao trabalho docente, da adoção de uma Identidade Profissional do Professor que abandona o ensino dos conteúdos escolares.

\section{Pedagogia Histórico-Crítica e Psicologia Histórico-Cultural e a centralidade da Educação Escolar}

Até o momento procuramos demonstrar que o discurso da Identidade Profissional do Professor, coaduna com as formas transitórias do profissionalismo exigido pela reestruturação produtiva do capital. Ao professor a demanda de uma formação massiva para uma sociedade com cada vez menos postos de trabalho, apresenta-se o repto de educar a força de trabalho para um capitalismo em crise permanente. No mesmo sentido, o próprio trabalho do professor é tomado pelos efeitos políticos da reestruturação, que se traduzem no enxugamento do Estado e drásticas reduções de investimentos na educação. Há nesse sentido um processo de desvalorização da força de trabalho docente ao mesmo tempo em que se complementa um esvaziamento do sentido de seu trabalho. Como resposta ao "malestar" ocasionado pelas mudanças estruturais da sociedade, a formação da sua identidade profissional, por meio da formação de um professor reflexivo é pautada como solução para a revalorização do sentido do seu trabalho. Uma de suas características, dentre outras, encontra-se o abandono do ensino dos conteúdos escolares. Em afinidade com as novas tecnologias e exigências do mercado de trabalho, o professor reflexivo não mais ensinaria conteúdos escolares previamente determinados, mas, formaria nos alunos "habilidades e competências", para enfrentar as situações de incerteza e conflito da sociedade contemporânea. Para fazer jus a sua Identidade Profissional, também na sua formação inicial, o domínio dos conteúdos escolares é colocado num segundo, ou talvez terceiro plano, já que o mais importante é que os professores aprendam a "conhecer-na-ação".

Por suposto expusemos o desenvolvimento histórico da profissão do professor, destacando a identificação do seu trabalho com o ensino, ao domínio dos conteúdos culturais, transmutados e transmitidos na forma de conteúdo escolar. No entanto, a identidade profissional que se propõe, em afinidade estrutural com as transformações político-econômicas do capital, afasta o professor da sua identificação com o ensinar. $\mathrm{O}$ que ainda nos falta esclarecer de fato é por que do abandono dos conteúdos escolares e quais as implicações negativas ao trabalho do professor e ao ato educativo?

Tendo em vista que trataremos aqui da concepção materialista histórica de conhecimento, tencionamos a compreender o lugar da educação escolar (da socialização do conhecimento) na intrincada dialética do desenvolvimento da consciência humana. Fundamental destacar que para Marx o "[...] aparecimento [da consciência] como um produto tardio do desenvolvimento do ser material" (LUKÁCS, 1978, p.3), corresponde à capacidade de captação e compreensão da realidade materializando-se em formas possíveis de "[...] intervir nessa realidade para modificá-la [...]" (LUKÁCS, 1978, p.3), o que significa também que em contrapartida a luta de classes, na disputa pelo excedente produzido pelo trabalho, há conseguintemente o litígio pelas consciências individuais dos homens, uma vez que:

[...] o saber real sobre os processos naturais que em cada oportunidade se põem em questão, foi inevitável para poder desenvolver com êxito o intercâmbio orgânico da sociedade com a natureza, do mesmo modo um certo saber sobre o modo pelo qual os homens são feitos, sobre as suas recíprocas relações sociais e pessoais, é aqui indispensável para induzilos a efetuar as posições teleológicas desejadas. (LUKÁCS, 1978, p.11) 
É mister, neste sentido, o domínio dos processos objetivos de transformação da natureza, bem como o controle sobre as posições teleológicas, a fim de que os homens ajam de maneira "socialmente desejada". Os homens não só desempenham ação sobre a natureza, como igualmente exercem influência sobre si mesmos. Em larga medida ${ }^{10} \mathrm{o}$ conhecimento se torna meio necessário para tornar os homens conscientes de sua atividade sobre o mundo, embora muitas vezes não seja possível "conhecer senão uma parte mínima das circunstâncias" (LUKÁCS, 1978, p.9). De outro modo, na medida em que na sociedade de classes o desenvolvimento da divisão do trabalho opera a separação entre o trabalho manual e o trabalho intelectual, o traço constitutivo dessa divisão consisti no alheamento das classes trabalhadoras do conhecimento objetivo da sociedade.

Em face disso, a compreensão da gravidade do fenômeno da alienação do conhecimento e suas consequências psicológicas e sociais, aponta para a necessidade do debate acerca da centralidade do conhecimento objetivo para o desenvolvimento qualitativo do psiquismo do homem, ou seja, para a formação de sua consciência. Neste plano, as perspectivas da Psicologia Histórico-Cultural e Pedagogia Histórico-Crítica, se apresentam como ferramentas teóricas que balizam a compreensão substancial dos processos psicológicos e fundamentos pedagógicos implicados no desenvolvimento histórico-cultural do pensamento e histórico-crítico do conhecimento.

É com esse espírito que Martins (2013) examina o papel desempenhado pela educação escolar no desenvolvimento do psiquismo humano. Ao dialogar com os aportes dos principais precursores da psicologia soviética ${ }^{11}$, Martins (2013) em sua tese de livre docência, estabelece uma ponte entre o desenvolvimento das funções psicológicas superiores e a centralidade do ensino sistêmico (na sua qualidade de educação escolar) das ciências, da filosofia e das artes na formação qualitativa do psiquismo. Daqui em diante, tomaremos ainda que resumidamente, alguns pontos da tese de Martins (2013), que consideramos fundamentais na elucidação da centralidade do ensino, para a formação da consciência humana.

Ao considerar a história do desenvolvimento do psiquismo, constata a natureza orgânica da relação entre os indivíduos e o meio como dado primário da evolução do cérebro humano. Tomando Leontiev como referência Martins (2013) explicita que:

[...] no processo de evolução biológica que conduz a evolução e diferenciação dos organismos, complexificam-se e diferenciam-se, sobretudo, os órgãos funcionais vitais responsáveis pelo referido intercâmbio. O desenvolvimento do cérebro insere-se nesse transito evolutivo como resultado da organização da matéria viva altamente organizada, por determinação do confronto entre o ser e a natureza. (MARTINS, 2013, p.20)

Com base nos estudos do psiquismo animal de Leontiev, Martins (2013, p.20) destaca o papel preponderante da atividade na "estruturação e na evolução do psiquismo". A atividade vital dos animais, orientada predominantemente pelos órgãos do sentido, possibilitou o surgimento de uma inteligência prática capaz de resolver os problemas concretos apresentados no nível do imediatismo, contudo condicionados aos limites de suas determinações biológicas. No ser humano, a atividade que dirige a sua sobrevivência se diferencia por reproduzir idealmente o resultado de sua ação, agindo desse modo, para além do imediatismo das circunstâncias e limitações biológicas (embora nunca possa eliminá-las por completo). Essa atividade é o trabalho. Assim, a complexificação das funções do cérebro humano seguindo tendências evolutivas próprias das espécies animais desenvolvidas com base no atendimento às necessidades biológicas e adaptativas ao meio, 
permitiu o surgimento do trabalho como atividade especificamente humana. O trabalho por sua vez possibilitou a criação da "a existência humana".

A partir do trabalho, as relações entre o homem e a natureza se modificam, a reprodução da espécie humana se liberta dos padrões biológicos de adaptação, invertendo a lógica natural de evolução a uma real transformação da natureza como objeto de satisfação de suas necessidades. Por conseguinte o próprio trabalho "[...] contém em si, desde o inicio, a possibilidade (dynamis) de produzir mais que o necessário para a simples reprodução daquele que realiza o processo de trabalho" (LUKACS, 2007, p.2), colocando para a humanidade um novo patamar de desenvolvimento. As propriedades do trabalho não só modificam a forma de relacionamento do homem com a natureza, transformando-a, como também modificam o modo do homem relacionar-se consigo mesmo, na medida em que "a fim de apropriar-se dos recursos da natureza externa [...] modificando-a, ao mesmo tempo modifica sua própria natureza." (MARX, 2010, p.211).

O trabalho se impõe desta forma como condição inicial e vital para o surgimento da existência humana, conduzindo consigo a humanização do cérebro humano e dos órgãos dos sentidos, alterando a condição de animalidade do psiquismo do homem a uma nova qualidade submetida agora pelas leis sócio-históricas do desenvolvimento.

Esse salto qualitativo, por meio do qual a vida do homem já não mais se fez garantida pela adaptação animal ao meio, tornou-se possível por um modo especial de intercâmbio com a natureza, isto é, pelo trabalho social. Por essa via a unidade funcional entre mãos, cérebro e linguagem conduziram ao aperfeiçoamento anatomofisiológico do córtex cerebral possibilitando um modo de relação entre o homem e as condições de existência marcado em definitivo pela mediação da consciência (MARTINS, 2013, p. 28).

A natureza social e coletiva do trabalho retroage sobre o conjunto dos homens criando objetivamente a consciência social de sua (re)produção. Expressamente essa consciência social se objetiva na linguagem, que desempenha não só o papel de meio de comunicação entre os homens como também "[...] torna-se a forma e o suporte da generalização consciente da realidade." (LEONTIEV, 2004, p.93). Prontamente, a consciência individual só poderia emergir nas condições de existência da consciência social, em sua definição Leontiev (2004) destacou que "a consciência é o reflexo da realidade refratada através do prisma das significações e dos conceitos linguísticos elaborados socialmente" (p.94). Seguindo esse entendimento Martins (2013) nos explica que

A consciência é a expressão ideal do psiquismo, desenvolvendo-se graças à complexificação evolutiva do sistema nervoso central pela decisiva influência do trabalho e da linguagem, inaugurando a transformação do ser orgânico em ser social. Com o advento da consciência, a realidade - e tudo o que a constitui - adquire outra forma de existência representada pela imagem psíquica, pela ideia que dela se constrói. (MARTINS, 2013, p. 28)

O que entra em jogo neste momento é formação da imagem no pensamento dos homens. Na constituição de sua sociabilidade os homens, por meio do trabalho (que é sempre atividade que se realiza num meio coletivo) e da linguagem, tomam consciência, elaboram ideias a respeito si mesmos e do mundo que o circunda. A formação das ideias 
decorre, portanto, da relação prática dos indivíduos no mundo e da posição que ocupam nestas relações. Em acordo com o materialismo dialético a gênese das ideias encontra-se na materialidade das ações concretas dos indivíduos construídas historicamente pelo modo como os homens se (re)produzem socialmente. Ipso facto o pensamento não poderia ser outra coisa senão a unidade material-ideal da ação humana sobre a natureza, unidade que "[...] firma-se como imagem subjetiva do real" (MARTINS, 2013, p.30)

Como ressalta Martins (2013) a imagem subjetiva da realidade objetiva não é a cópia imediata do real, como a princípio os indivíduos captam a realidade circundante sensorialmente, suas impressões sobre o mundo, nem sempre o representam fielmente, formando ideias que não se confirmam na realidade. Como na maioria dos casos a fidelidade da imagem está comprometida com momentos decisivos para a continuidade de certo modo de existência social, a veracidade das ideias fundamentais à produção da vida em sociedade é aferida pelo trabalho que "[...] necessariamente colocará em xeque a qualidade a eficácia e a fidedignidade da imagem, sua veracidade será aferida objetiva e praticamente na consecução de seus fins teleológicos [...]” (MARTINS, 2013, p.32). Assim as imagens na sua máxima aproximação com o movimento do real, representam na cabeça dos homens as leis objetivas da realidade.

No trabalho a precisão das ideias afeta cabalmente o seu resultado. Face ao desenvolvimento e complexidade das ações ordenadas e coordenadas pelo trabalho, o contato entre os homens na sua consecução demanda um tipo especial de comunicação que permita fixar extemporaneamente (sendo transmitidas de uma geração a outra) as ideias essenciais das leis que regem a materialidade dos objetos do trabalho. Para colocar em movimento um determinado tipo de trabalho, é necessário suscitar em outros homens (nas outras gerações vindouras) comportamentos apropriados à forma predominante de intercâmbio com a natureza. Para nós implica confirmar seguramente que o trabalho não somente permitiu aos homens a formação de ideias sobre os objetos, como também, a formação de ideias sobre o próprio comportamento humano, de forma a influir sobre a consciência individual dos homens. De modo que o meio desenvolvido para condensar e expressar as ideias que por um lado comunique e por outro provoque nos indivíduos o acionamento de condutas que sejam almejadas socialmente, tenha no signo o seu veículo de propagação.

É Vigotski, no entanto, quem decifrou o curso do desenvolvimento histórico cultural do psiquismo, descobrindo no emprego do signo a base do progresso interfuncional da estrutura psíquica humana. Desta maneira nos revela Martins (2013)

O signo opera então como estímulo de segunda ordem que retroagindo sobre as funções psíquicas, transforma suas expressões espontâneas em expressões volitivas. As operações que atendem aos estímulos de segunda ordem conferem novos atributos às funções psíquicas, e por meio deles o psiquismo humano adquire um funcionamento qualitativamente superior e liberto tanto dos determinismos biológicos quanto do contexto imediato da ação (p. 44)

O signo opera a "virada" do desenvolvimento do psiquismo. Por sobre os pilares do desenvolvimento sócio-histórico, não são mais os fatores biológicos que dirigem o processo de funcionamento intra-psíquico, igualmente, por obra do emprego do signo as funções psicológicas elementares (ocorrem em direta dependência do amadurecimento orgânico), se transformam em processos artificiais que demandam o desenvolvimento de funções psíquicas superiores. 
Por conseguinte, tais transformações ocorrem sem nenhuma alteração fenotípica ou genotípica no homem, dado que atesta que "[...] o referido desenvolvimento é produto da vida social e não biológica, portanto, essa condição deve ser tomada como o aspecto mais decisivo no desenvolvimento cultural do comportamento [...]" (MARTINS, 2013, p.79, grifo nosso)

De tal forma se entrecruzam as linhas de desenvolvimento onto e filogenético uma vez que inseridos numa realidade socialmente transformada (natureza inorgânica), o desenvolvimento biológico dos indivíduos desde a mais tenra idade entra em "choque" com as formas culturais complexas já desenvolvidas ou em desenvolvimento, de modo que a apropriação dos signos da cultura se coloca como condição para o desenvolvimento das "formas superiores de comportamento".

Deste modo os indivíduos inseridos socialmente se afastam cada vez mais de qualquer adaptação passiva ao meio natural, sua reprodução e desenvolvimento são encarados cada vez mais em termos sociais, instauradas no curso de sua ação prática e no interior da prática social que se cristaliza e se solidifica em determinadas ações, tornandoas tão naturais como as essencialmente naturais, mas determinadas única e exclusivamente pela estrutura social, pelo "modo de vida" que os indivíduos assumem e são levados a assumir pelo decurso histórico da sociedade. Defronte as formas socialmente instituídas, se tornam decisivos o domínio dos objetos da cultura que promovam o desenvolvimento das funções psicológicas superiores, implicadas no "domínio do homem sobre a natureza $e$ sobre si mesmo", de forma mais abrangente a apropriação "da linguagem, do calculo, da escrita, da pintura" (MARTINS, 2013, p. 104)

Para a Psicologia Histórico-Cultural a humanidade é produto da ação do homem sobre a natureza, ela não existe $a$ priori como dádiva, ou fruto da evolução biológica e por esse motivo ela precisa ser reproduzida nos indivíduos. A consciência como obra dessa interação entre homem e natureza, na qual o ser social "põe em movimento as forças naturais do seu corpo - braços e pernas, cabeça e mãos -, a fim de apropriar-se dos recursos da natureza, imprimindo vida útil à vida humana" (MARX, 2010, p.211), também só pode se desenvolver com base nas relações sociais estabelecidas em face do advento da linguagem e emprego dos signos culturais.

Desta forma para a psicologia histórico-cultural o ensino do signo, ou melhor, das formas complexas ou culturais de comportamento é a atividade que irá dirigir o desenvolvimento qualitativo da consciência nos indivíduos. Daí a importância do ensino escolar para Vigotski que via nos conceitos científicos as formas mais elaboradas do pensamento, por representarem o mais alto grau de conquista da humanidade, posto que,

A questão do desenvolvimento dos conceitos científicos na idade escolar é antes de tudo, uma questão prática de enorme importância, que pode ser primordial do ponto de vista das tarefas a que se propõe a escola ao ensinar à criança o sistema de conhecimentos científicos [...] Ademais um significado teórico muito importante, uma vez que a investigação do desenvolvimento dos conceitos científicos, quer dizer, dos conceitos autênticos, verdadeiros, pode nos permitir descobrir as regularidades mais profundas, mais fundamentais de qualquer processo de formação dos conceitos em geral. (VIGOSTKI, 2001, apud MARTINS, 2013, p.179)

Nesta mesma linha de compreensão da centralidade do ensino para o desenvolvimento dos indivíduos que Martins (2013) situa a Pedagogia Histórico-Crítica. Para Saviani (2012) a natureza e especificidade da educação escolar "diz respeito ao conhecimento elaborado e não ao conhecimento espontâneo; ao saber sistematizado e não 
ao saber fragmentado; à cultura erudita e não à cultura popular" (p. 14). A educação escolar exerce neste sentido um papel privilegiado na formação cultural dos indivíduos, na medida em que ela sintetiza o conhecimento científico, os conceitos autênticos, convertendo-os em conteúdos escolares. Contudo, não basta o conhecimento por si só, é preciso torná-lo inteligível, viabilizando sua transmissão e apropriação pelos indivíduos. Com efeito, todas as concepções burguesas de educação, tendencialmente flexionaram o ensino ao reconhecimento das potencialidades naturais dos indivíduos, quando muito, o invalidaram como forma adequada de educação. A Pedagogia Histórico-Crítica por outro lado vê no ensino sistematizado, uma forma de saber escolar, no qual, é fundamental ao ato educativo distinguir os conhecimentos, as formas de transmiti-los, de modo que promova a humanidade nos indivíduos. As pedagogias burguesas embora não prescindam do ensino escolar, o vêm como perigoso ao desenvolvimento das individualidades, uma vez que tende a homogeneizar o saber, um conhecimento igual para todos, pode prejudicar deste modo a descoberta e o cultivo dos talentos adormecidos. No contraponto, a Pedagogia Histórico-Crítica reconhece o ensino escolar como condição para o desenvolvimento da individualidade, colocando na pauta política a apropriação dos saberes sistematizados como perspectiva da luta da classe trabalhadora.

Considerando então que a humanidade não "nasce" nas pessoas a partir delas mesmas, mas resulta da humanidade objetivada e disponibilizada às suas internalizações, a psicologia histórico-cultural e a pedagogia histórico-crítica não são indiferentes à analise das condições objetivas que, em uma sociedade de classes, reservam para diferentes indivíduos condições desiguais de humanização. Mais do que não serem indiferentes, essas teorias evidenciam a necessidade de superação da ordem econômica fundada na propriedade privada dos produtos do trabalho humano, no que se inclui o produto do trabalho intelectual. (MARTINS, 2013, p. 272)

Retomando, para a pedagogia histórico-crítica e a psicologia histórico-cultural a centralidade do conhecimento se coloca umbilicalmente ao processo de tornar-se homem, fundamentalmente para a tomada de consciência da realidade objetiva e de si mesmo. Nessa direção é importante frisar que, conquanto o trabalho do professor seja fundamental para a promoção das capacidades tipicamente humanas destacadas das formas culturais de comportamento, o mediador do processo educativo, não é o professor "em-si-mesmado" que isolado, tira conclusões próprias de sua prática educativa. Como ressalta Vigotski o signo é a mediação é o "meio de que o homem se vale para influenciar psicologicamente, seja na sua própria conduta, seja nas dos demais [...]" (VIGOTSKI, 2001, apud MARTINS, 2013, p.46), nesse sentido só pode provocar mudanças significativas no aprendizado dos indivíduos o professor que for portador de signos. Compete para a formação do professor um sólido embasamento teórico e um amplo campo de experiência para o ensino. Nessa perspectiva o domínio do conhecimento e das formas de sua transmissão se insere como condição primeira ao exercício da docência. No ponto seguinte trataremos dessa questão com maior acuidade, apontando essencialmente alguns pontos críticos da Identidade profissional do professor, adida ao referencial teórico do professor reflexivo. 


\section{Apontamentos críticos: os limites da identidade profissional do professor.}

O caminho que percorremos procurou demonstrar que o discurso que visa à construção da Identidade profissional docente especifica a prática reflexiva como modelo de profissionalismo, capaz de superar a crise de identidade docente instada a partir das "mudanças" ocorridas nas formas de ensinar e aprender. Uma de suas características é o abandono do ensino dos conteúdos escolares, assumindo para si a tarefa de formar e desenvolver competências e habilidades que correspondam as exigências da "nova organização do trabalho" "12. Deste modo, estaria em curso a construção de uma identidade profissional do professor que não se identifica com o ensino escolar propriamente dito. De certa forma procuramos demonstrar o quanto o ensino escolar incide no desenvolvimento dos indivíduos, destacando a sua centralidade para a psicologia histórico-cultural e pedagogia histórico-crítica, retratando a sua importância para formação do professor. Propomos-nos a discutir, neste ponto, os limites da identidade profissional do professor, partindo das elucidações já produzidas a respeito do ensino escolar. Entretanto, daremos início a nossos apontamentos reportando-nos a uma passagem do artigo de Eric Hobsbawm, no qual ele discute a universalidade da história e a busca da identidade.

Em visita à província italiana de Arezzo, Hobsbawm (2013) é convidado a participar de um congresso de historiadores para discutir os massacres produzidos pelos nazistas durante a Segunda Guerra Mundial em Civitella della Chiana. Até então, cinquenta anos após o acontecido, o tema não havia sido tratado com tanto apreço pelos meios acadêmicos, tendo as memórias deste evento, ficado reservadas aos aldeões que sobreviveram e aos historiadores locais da Resistência Italiana. Tratava-se do fuzilamento de cento e setenta e cinco moradores, que tinham colaborado com a Resistência, assassinados e despejados no crematório de sua aldeia. Diante das atrocidades perpetradas pelo exército alemão, o tema que se apresentava já despontava como incômodo para a maioria dos debatedores que tinham a sua frente, familiares e reminiscentes da tragédia de guerra. No entanto, como narra Hobsbawm (2013) o maior incômodo vinha por parte do "soterramento" das lembranças da Resistência contra Hitler e Mussolini. Por parte de um acordo tácito os aldeãos haviam enterrado o passado conflituoso para retomar a "normalidade" de suas vidas.

Historiadores orais, jovens e presumivelmente esquerdistas haviam entrevistado e reentrevistado os aldeões na preparação da conferência, estavam chocados por descobrirem que os habitantes, pelo menos de uma aldeia muito católica, não culpavam tanto os alemães pelo massacre quanto os jovens locais que haviam se juntado aos guerrilheiros e, segundo achavam, haviam irresponsavelmente levado seus lares ao desastre. (HOBSBAWM, 2013, p.365)

A memória dos aldeões contrariava a lógica universalista da história, a experiência pessoal ditada pelos padrões locais, afirmava a "normalidade" da vida contra o movimento histórico, aqueles que saíram do cotidiano arriscando suas vidas por mudanças, eram os únicos culpados por seu infortúnio. Os historiadores de várias nacionalidades (inclusive alemães) estavam chocados com o ajuste realizado pela micro-história e a incompatibilidade entre a história universalista da academia e o modo particular como aquelas pessoas construíram a sua identidade histórica. Para contra-argumentar a história local, os historiadores ali reunidos se municiaram dos critérios científicos fundamentados nas evidências dos fatos, referências e citações, "em suma, nenhuma ocasião poderia ter dramatizado melhor o contraste entre a universalidade e a identidade na história, e o 
confronto dos historiadores tanto com o passado quanto com o presente". (HOBSBAWM, 2013, p.367 grifo nosso)

A identidade dos aldeões com o seu modo de vida e sua história, teve de ser quebrada pela universalidade do conhecimento. Como ressalta Hosbsbawm (2013), pelo menos naquele momento, para os historiadores ficava evidente que "[...] a universalidade prevalecia sobre a identidade" (p.367) e que só era relevante para a história universal as memórias dos aldeões que fossem balizadas pelos "critérios universalmente aceitos pela disciplina”.

Dessa passagem retratada por Hosbsbawm, enfatizamos alguns questionamentos para a nossa crítica a identidade profissional do professor. Em que medida pode superar a "crise de identidade", uma identidade circunscrita a sua particularidade? Como pode uma identidade do professor que abandona os conhecimentos universais e os "critérios universamente aceitos pela disciplina", corresponder com os objetivos da profissão (promover a humanidade nos indivíduos)? Como pode existir uma identidade profissional do professor que não ensina?

De fato a identidade está inserida num prospecto particular da ação dos indivíduos, àquilo que está imediatamente posto. Em larga medida os indivíduos se identificam com o experienciado, muito embora seja correto afirmar que só é possível identificar-se com aquilo que é conhecido. Contudo o conhecimento que pode determinar a constituição de uma ou outra identidade pode prescindir da episteme e se apoiar nos conhecimentos do senso comum e da experiência de vida, que nem sempre exigem comprovação com o real. Limitada assim à sua própria particularidade, a identidade do professor que não tem como finalidade a identificação dos elementos essenciais para a realização do trabalho docente, que não leva em conta as múltiplas determinações da sua atividade, tende a postular soluções que em ultima instância corroboram com a situação de "mal-estar" da profissão, incorrendo num confuso exercício apologético das forças motoras da crise identitária profissional.

Destarte, estamos convencidos de que a crise permanente do capital detectada na década de 1970, que ao reorganizar a produção de modo a tornar possível reaver e ampliar a lucratividade - mesmo que isso signifique a expulsão de uma grande massa de trabalhadores do mercado de trabalho - é a força motora, que de fato e de direito tem causado as "mudanças" na sociedade. Da mesma forma o trabalho do professor em educar a força de trabalho deste sistema em crise, à medida que torne possível satisfazer as necessidades da produção, encravando na sociedade a marca do "novo profissionalismo" exigido por uma dinâmica de autoexpansão do capital, implica na adoção de novos critérios (cada vez mais subjetivos) de seleção, para um modelo social que promove o desemprego crônico (MÉSZÁROS, 2006). Não muito distante disso, o próprio trabalho docente em atenção aos imperativos da produção também se adéqua, de modo a garantir o pleno alargamento da crise estrutural, sendo orientado desta maneira a educar hoje o desempregado de amanhã.

Política e estruturalmente o trabalho docente ${ }^{13}$ tem sofrido com a desvalorização (impresso nas perdas salariais da categoria) e esvaziamento (decadência do sentido da profissão), refletindo a crise de sua identidade. De modo bastante convincente as análises sobre os efeitos da crise colocam em questão a função precípua do professor. A transmissão de conhecimentos deixa de ser o centro de sua ação. O saber objetivo encarece o preço da força de trabalho, além de, em muitos casos, pode contrapor-se às necessidades da produção. Basta conhecer o que precisa ser feito, a massa dos trabalhadores despojada agora dos conhecimentos técnico-científicos da profissão precisa aprender a se comportar taxativamente em conformidade com os imperativos do mercado, buscando "soluções 
criativas" aos obstáculos do capital. Ademais, como já demonstramos, o ensino dos conteúdos escolares implica na constituição das funções superiores do psiquismo, o que em tese nos habilita a afirmar que a sua renúncia resulta em uma formação limitada aos estímulos mais elementares colocando em jogo o desenvolvimento do pensamento abstrato e a própria personalidade ${ }^{14}$ dos indivíduos. Reiterativamente, forma indivíduos limitados às suas relações imediatas e cotidianas, em nossa sociedade equivale dizer que são cada vez mais subordinados aos imperativos do capital ${ }^{15}$ e as imposições objetivas da produção de mais valia. Em consequência disso e somente em conformidade com a "flexibilidade" da produção é possível admitir a formação uma identidade profissional do professor que não se identifica com o ensino.

Isso se traduz objetivamente em um praticismo pedagógico descolado da realidade social e da política econômica, atribuindo "uma importância decisiva para aquilo que 'a vida ensina', destacando como principais recursos da formação [de professores] a experiência e a personalidade dos formandos" (MARTINS, 2007, p.20). Os problemas da prática educativa como elucida Martins (2007) são resolvidos no âmbito da experiência pessoal, distanciando, o trabalho docente de análises mais complexas sobre a estrutura sociopolítica que determina as relações no interior da escola. Na mesma proporção a (pseudo)valorização das conquistas pessoais, em absoluto nos interstícios da prática cotidiana e na solução pontual dos problemas apresentados por ela, absorvem os indivíduos para a integração estrutural à raiz dos problemas sociais que afetam a escola. No mais se convertem em estratégias de adaptação dos sujeitos, que "empobrecidos" material e intelectualmente se veem à deriva de um projeto de sociedade. Sorrateiramente a insuficiência de conteúdos formadores atua minando as perspectivas emancipatórias, apresentando a realidade periclitante do capital como uma potência acima dos homens, a concorrência, o livre-mercado e o trabalho alienado, aparecem perenemente sob formas "naturalizadas" das quais pobreza e riqueza emanam.

Particularmente o critério de identidade profissional parece insuficiente para caracterizar o essencial do trabalho docente. Para nós, cada vez mais se torna clara a necessidade de superar a questão da identidade do professor e olhar para a essencialidade do seu trabalho, naquilo que ele é integralmente, apontando suas características emancipadoras "como atividade por meio da qual os indivíduos se apropriam das objetivações humanizadoras produzidas pelos homens histórica e socialmente [...]" (MARTINS, 2007, p. 25).

\section{Conclusão}

Diante do exposto é preciso reafirmar o compromisso da formação docente com o conhecimento objetivo produzido e acumulado histórica e socialmente pelo conjunto da humanidade. Em que pese, superar os discursos identitários, distinguindo "[...] o essencial e o acidental, o principal e o secundário, o fundamental e o acessório [...]" (SAVIANI, 2012, p.13) da prática docente.

A identidade profissional do professor apoiada na epistemologia da prática dilui o trabalho docente num pragmatismo pedagógico, onde o essencial da prática docente aparece como ocasional. Substituindo o ensino dos conteúdos escolares, por "competências e habilidades", o profissionalismo do professor fixa sua identidade aos processos contemporâneos de expropriação do trabalho, ditados pela reestruturação produtiva e pela política neoliberal. A superação da suposta crise de identidade se acopla a um processo de adaptação do trabalho docente às exigências de formação da força de trabalho (incluindo o próprio professor neste processo) para a produção flexível de um capitalismo em crise. 
O abandono do ensino dos conteúdos escolares como novo requisito ao profissionalismo docente do século XXI acarreta consequências problemáticas tanto para o trabalho educativo, quanto para o desenvolvimento humano dos alunos. O professor circunscrito em sua prática e destituído dos conhecimentos universais, dificilmente irá desenvolver sua função precípua, ou seja, promover a humanidade nos indivíduos. Assim, segundo os estudos da Psicologia Histórico-Cultural, para o desenvolvimento das funções psicológicas superiores e dos comportamentos culturais complexos é necessário a apropriação do signo em suas formas mais desenvolvidas. Tal processo não ocorre naturalmente é preciso, neste sentido, ensinar os signos da cultura de uma geração para a outra. Entretanto, não é qualquer aprendizagem que promove o desenvolvimento do psiquismo, mas, como dito por Vigotski, apenas aquelas que se adiantam ao desenvolvimento. Os conceitos científicos se tornam fundamentais neste processo. Neste sentido, para a Psicologia Histórico-Cultural e a Pedagogia Histórico-Crítica, a centralidade da educação escolar encontra-se no próprio ato de ensinar, destacando a superioridade dos conceitos científicos sobre os conceitos espontâneos. Para ensinar é preciso, portanto, identificar os "elementos culturais que precisam ser assimilados pelos indivíduos da espécie humana para que eles se tornem humanos e, de outro lado e concomitantemente, a descoberta das formas mais adequadas para atingir esse objetivo" (SAVIANI, 2012, p.13). De outro modo um professor que não se identifica com o ensino dificilmente irá identificar-se com sua profissão, tornando-se presa fácil para os discursos voluntaristas e pragmáticos que se unem em busca de soluções úteis e práticas às carências escolares. Quanto mais, destituído de um projeto de emancipação do homem, a identidade profissional do professor reflexivo, ajusta a educação dos indivíduos à realidade dada do capital, se entregando aos imperativos da empregabilidade e da necessidade de adequação da força de trabalho às competências exigidas pelo mercado. É preciso, contudo, avançar na compreensão da identidade do professor e ultrapassá-la no que tange à busca dos critérios que registrem a universalidade de sua ação, ou senão, presos a particularidade, como os aldeões de Arezzo, corremos o risco de agir coroando os algozes e culpando nossos aliados.

\section{Referências}

CUNHA, M. V. John Dewey: uma filosofia para educadores em sala de aula. 2. ed. Petrópolis: Vozes, 1998.

CANDIDO, R. M. Culturas da Escola: as festas nas escolas públicas paulistas (18901930). UNIVERSIDADE DE SÃO PAULO, Dissertação de Mestrado. 2007, 155 p.

CARVALHO S. R. e MARTINS L. M. A escola pública e as competências para o mercado: realidade e mitos. Revista Semestral da Associação Brasileira de Psicologia Escolar e Educacional, SP. Volume 17, Número 1, Janeiro/Junho de 2013, p.141-149.

DUARTE, N. As pedagogias do "aprender a aprender" e algumas ilusões da assim chamada sociedade do conhecimento. Revista Brasileira de Educação, n.18, 2001. p.3540 .

FACCI, M. G. D. Valorização ou esvaziamento do trabalho do professor? Um estudo crítico comparativo da teoria do professor reflexivo, do construtivismo e da psicologia vigotskiana. Campinas: Autores Associados, 2004.

HAYEK, F. O caminho da servidão. Porto Alegre: Globo, 1977. 
HOBSBAWM. E. Não basta a história de identidade. In: HOBSBAWM. E. Sobre a História: ensaios. São Paulo: Companhia das Letras, 2013.

LEONTIEV, A. O desenvolvimento do psiquismo. Tradução do francês de Rubens Eduardo Frias. 2ed. São Paulo: Centauro, 2004.

LUKÁCS, G. Ontologia do ser social: a reprodução. Tradução provisória de Ivo Tonet. Versão digital enviada por <ivo_tonet@yahoo.com.br> em 16 de maio de 2007. p.1-116

LUKÁCS, G. As bases ontológicas do pensamento e da atividade do homem. Trad. Carlos Nelson Coutinho. Temas de Ciências Humanas, $n^{\circ}$ 4, p. 1-18. São Paulo: Ciências Humanas, 1978.

MARTINS, L. M. A formação social da personalidade do professor: um enfoque vigotskiano. Campinas: Autores Associados, 2007. (Coleção formação de professores)

MARTINS, L. M. O desenvolvimento do psiquismo e a educação escolar: contribuições à luz da psicologia histórico-cultural e da pedagogia histórico-crítica. Campinas: Autores Associados, 2013.

MARX, K. O Capital: o processo de produção do capital. Livro1. Volume I. 27. ed. Rio de Janeiro: Civilização Brasileira, 2010.

MÉSZÁROS, I. Para além do capital: rumo a uma teoria da transição. Tradução de Paulo

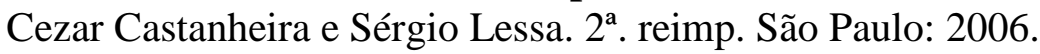

PERRENOUD, P. Construir as competências desde a escola. Trad. Bruno Charle Magne. Porto Alegre: Artmed, 1999.

PERRENOUD, P. Dez novas competências para ensinar. Trad. Patrícia Chittoni Ramos. Porto Alegre: Artes Médicas Sul, 2000.

PIMENTA, S. G. Formação de professores: saberes e identidade. In: PIMENTA, S.G. (org) Saberes pedagógicos e atividade docente. São Paulo: Cortez, 1999.

PIMENTA, S. G. Pedagogia e pedagogos: caminhos e perspectivas. São Paulo: Cortez, 2002.

PIMENTA, S. G e LIMA, M. S. L. Estágio e docência. 3ª ed. São Paulo: Cortez, 2008.

PINTO, J. M. R e outros. O financiamento do ensino médio no Brasil: de uma escola boa para poucos à massificação barata da rede pública. Educação e Sociedade, Campinas, v. 32, n. 116, p. 639-665, jul.-set. 2011. Disponível em <http://www.cedes.unicamp.br> acesso em: 22 de dezembro de 2013.

ROBERTSON, S. L. Política de re-territorialização: espaço, escala e docentes como classe profissional. Currículo sem Fronteiras, v.2, n.2, p.22-40, julho a dezembro de 2002.

Disponível em: < http://www.curriculosemfronteiras.org/vol2iss2articles/robertson.pdf> acesso em: 22 de dezembro 2013.

SAVIANI, D. Formação de professores: aspectos históricos e teóricos do problema no contexto brasileiro. Revista Brasileira de Educação v. 14 n. 40 janeiro/abril de 2009.

SAVIANI, D. História das ideias pedagógicas no Brasil. $3^{\text {a }}$.ed.Campinas: Autores Associados, 2011.

SAVIANI, D. Pedagogia Histórico-Crítica: primeiras aproximações. $11^{a}$.ed.Campinas: Autores Associados, 2012. 
SCHAFF, A. A sociedade informática. São Paulo: Editora Unesp, 1990.

SCHÖN, D. Educando o profissional reflexivo. Tradução de Roberto Cataldo Costa. Porto Alegre: Artmed, 2000.

SODRÉ, N. W. Brasil: radiografia de um modelo. 5ed. Petrópolis: Vozes, 1982.

TEIXEIRA, L. Pedagogia Histórico-Crítica: contribuições para a superação do conhecimento tácito na formação de professores. In: MARSíGLIA, A. C. G. (org.) Infância e Pedagogia Histórico-Crítica. Campinas: Autores Associados, 2013.

ZEICHNER, K. M. Formação reflexiva de professores. Lisboa: Educa, 1993

ZEICHNER, K. M. Repensando as conexões entre a formação na universidade e as experiências de campo na formação de professores em faculdades e universidades. Educação. Santa Maria, v. 35, n. 3, p. 479-504, dez. 2010.

\footnotetext{
${ }^{1} \mathrm{O}$ presente trabalho foi realizado com apoio do CNPq, Conselho Nacional de Desenvolvimento Científico e Tecnológico - Brasil.

${ }^{2}$ Professor Colaborador da Universidade Estadual do Centro Oeste do Paraná (UNICENTRO/Guarapuava). Doutorando do Programa de Pós-Graduação em Educação Escolar da Universidade Estadual Paulista "Júlio de Mesquita Filho" (UNESP/FC/Araraquara). Bolsista CNPq.

${ }^{3}$ Massachussetts Institute of Technology.

${ }^{4}$ Há algumas críticas à concepção de Schön, principalmente por parte de autores que usam sua teoria como referência, só para citarmos, as apresentadas por (PIMENTA, 1999, 2002), (PIMENTA e LIMA, 2008), (ZEICHNER, 1993, 2010). Críticas que não alteram substancialmente sua proposta original da prática reflexiva.

${ }^{5}$ Neste livro Donald Schön discute a epistemologia da prática para o ensino profissional.

${ }^{6}$ Desenvolvido na Inglaterra por Joseph Lancaster e também conhecido como método lacasteriano, baseavase no principio da monitoração, aproveitando o conhecimento dos alunos mais avançados para auxiliar o trabalho do professor, permitindo o controle de salas de aula numerosas. Segundo Saviani (2011) “o método supunha regras predeterminadas, rigorosa disciplina e a distribuição hierarquizada dos alunos sentados em bancos dispostos num salão único e amplo. De uma das extremidades do salão, o mestre, sentado numa cadeira alta, supervisiona toda a escola, em especial os monitores". (p.128)

${ }^{7}$ Setores da sociedade civil, como a CNI (Confederação Nacional da Indústria), a TFP (Tradição Família e Propriedade), tiveram um papel importante para a configuração e defesa, nos primeiros anos do golpe.

${ }^{8}$ Mészáros (2006) nos explica que a crise de acumulação capitalista está ligada aos limites estruturais do aumento das taxas de lucro, uma vez que os investimentos no capital se tornam maiores que o lucro obtido, unindo isso à impossibilidade de deslocamento das contradições locais, resta ao capital expandir seus limites de exploração, intensificando a extração de mais-valia e diluindo a crise econômica nos outros complexos sociais, acarretando numa crise estrutural do capitalismo.

${ }^{9}$ Ver Duarte (2001)

${ }^{10}$ Afirmamos que seja em "larga medida", pois existem outras formas de tornar os homens conscientes de suas atividades práticas, como a religião, o costume, a tradição, que muito embora tenham um caráter de saber, prescindem da objetividade do conhecimento científico.

${ }^{11}$ Vigotski, Luria e Leontiev.

12 Nós reconhecemos as "novas formas de trabalho" como reflexo da reestruturação produtiva do capital.

${ }^{13}$ Robertson (2002, p. 30) nos indica que "em muitos países os salários para o magistério e as negociações acerca deles organizaram-se, centralmente, no período pós-guerra (por exemplo, no Reino Unido, na Grécia, na Austrália e Nova Zelândia). Contudo, à medida em que os estados competitivos buscaram reduzir seus gastos totais com a educação, as margens de redução foram contidas pelo percentual dos salários do professorado em relação aos custos totais dos financiamentos em educação (os gastos com salários para o magistério variam entre 60 e $90 \%$ - OCDE, 1999)"

${ }^{14}$ Para o Materialismo Dialético o psiquismo humano radica na formação da imagem subjetiva da realidade objetiva, o grau de fidedignidade da imagem objetiva é o que vai orientar os sujeitos na realidade e na relação consigo mesmo, configurando um processo de personalização (MARTINS, 2013)

${ }^{15}$ A lucratividade, o consumismo, o desperdício, a empregabilidade.

Recebido: maio-15 Aprovado: agosto-15
} 